\title{
Implementation and investigation of circular slot UWB antenna with dual-band-notched characteristics
}

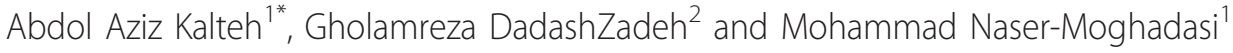

\begin{abstract}
The design and analysis of an ultra wideband aperture antenna with dual-band-notched characteristics are presented. The proposed antenna consists of a circular ring exciting stub on the front side and a circular slot on the back ground plane. By utilizing a parasitic strip and a T-shaped stub on the antenna structure, two notched bands of $850 \mathrm{MHz}(3.5-4.35 \mathrm{GHz})$ and $900 \mathrm{MHz}(5.05-5.95 \mathrm{GHz})$ are achieved. The proposed antenna is fabricated and measured. Measured results show that this antenna operates from $2.3 \mathrm{GHz}$ to upper $11 \mathrm{GHz}$ for voltage standing wave ratio less than 2, except two frequency notched bands of 3.5-4.35 and 5.05-5.95 GHz. Moreover, the experimental results show that proposed antenna has stable radiation patterns and constant gain. A conceptual circuit model, which is based on the measured impedance of the proposed antenna, is also shown to investigate the dual-band-notched characteristics.
\end{abstract}

Keywords: ultra-wideband antennas, microstrip slot antennas, band-notched antennas

\section{Introduction}

Since the Federal Communications Commission (FCC) first approved rules for the commercial use of ultra wideband (UWB) in 2002 [1], the feasible design and implementation of UWB system has become a highly competitive topic in both academy and industry communities of telecommunications. Antennas are the particularly challenging aspect of UWB technology. To satisfy such a requirement, various wideband antennas have been studied [2-5]. Challenges of the feasible UWB antenna design include the UWB performances of the impedance matching and radiation stability, the compact appearance of the antenna size, and the low manufacturing cost for consumer electronics applications [6]. The UWB communication systems use the $3.1-10.6 \mathrm{GHz}$ frequency band, unfortunately there are some other existing narrowband services that already occupy frequencies in the UWB band, such as the C-band (3.7-4.2 GHz) satellite communication systems and wireless local-area network (WLAN) IEEE802.11a and HIPERLAN/2

\footnotetext{
* Correspondence: Aziz_kalteh@yahoo.com

${ }^{1}$ Science and Research Branch, Faculty of Engineering, Islamic Azad University, Tehran, Iran

Full list of author information is available at the end of the article
}

WLAN operating in the $5.15-5.825 \mathrm{GHz}$ band. Therefore, UWB communication systems may cause unwanted interference with other co-existing communication systems. To overcome problems caused by this electromagnetic interference, various UWB antennas with single or multiple notch functions have been developed for UWB communication systems [7-14].

In this article, based on designs presented in [5,10], a circular slot UWB antenna with dual-band-notched characteristics is presented. The proposed antenna composed of circular ring exciting stub on the front side and a circular slot on the back ground plane. To achieve dual-bandnotched characteristics at frequency band of WLAN and C-band satellite communication systems, a parasitic semicircular annular strip and a T-shaped stub are utilized on the antenna structure, respectively. Effects of varying the parameters of the notch functions on performance of antenna have also been studied. Performance simulations of the antenna were performed with Ansoft HFSS10.0 and CST Microwave Studio 5.0 software $[15,16]$.

A conceptual circuit model, which is based on the measured impedance of the proposed antenna, is also shown for investigating the dual-band-notched characteristics. Designed antenna with optimal dimensions was 
fabricated and measured. An extensive comparison between experimental and simulation results is made, which demonstrates good agreement over approximately the entire operating frequency range.

The remaining of this article organized as follows: Section 2 presents the configuration of proposed antenna, parametric study of antenna is investigated in Section 3. The simulated and measured results are discussed in Section 4, and finally the conclusion is provided in Section 5.

\section{Antenna configuration}

The geometry of the proposed circular slot UWB antenna possessing band-notched function is depicted in Figure 1, with its geometry parameters. The antenna is located on the $x-y$ plane and the normal direction is parallel to $z$-axis. The proposed antenna is fabricated on a dielectric substrate of FR4 epoxy substrate with relative permittivity $\left(\varepsilon_{\mathrm{r}}\right)$ of 4.4 , thickness of $1.6 \mathrm{~mm}$, and ground plane size of $L_{\mathrm{g}} \times W_{\mathrm{g}}=45 \times 40 \mathrm{~mm}$. For this antenna, the radiation element consists of a circular slot with radius of $R$, i.e., fed by a circular ring resonator line with inner and outer radiuses of $r_{\mathrm{i}}$ and $r_{\mathrm{o}}$, respectively. This ring is connected to the $50 \Omega$ main line with $W_{f}=3 \mathrm{~mm}$ (see Figure 1a).

To overcome the unwanted electromagnetic interferences of UWB communication systems with IEEE 802.11a and HIPERLAN/2 WLAN and C-band satellite communication systems, a parasitic semicircular annular strip and T-shaped stub are utilized on antenna structure. The parasitic strip is attached to reject the frequency band of WLAN (5.15-5.825 GHz) and T-shaped stub is used to eliminate the frequency band of 3.7-4.2 GHz.

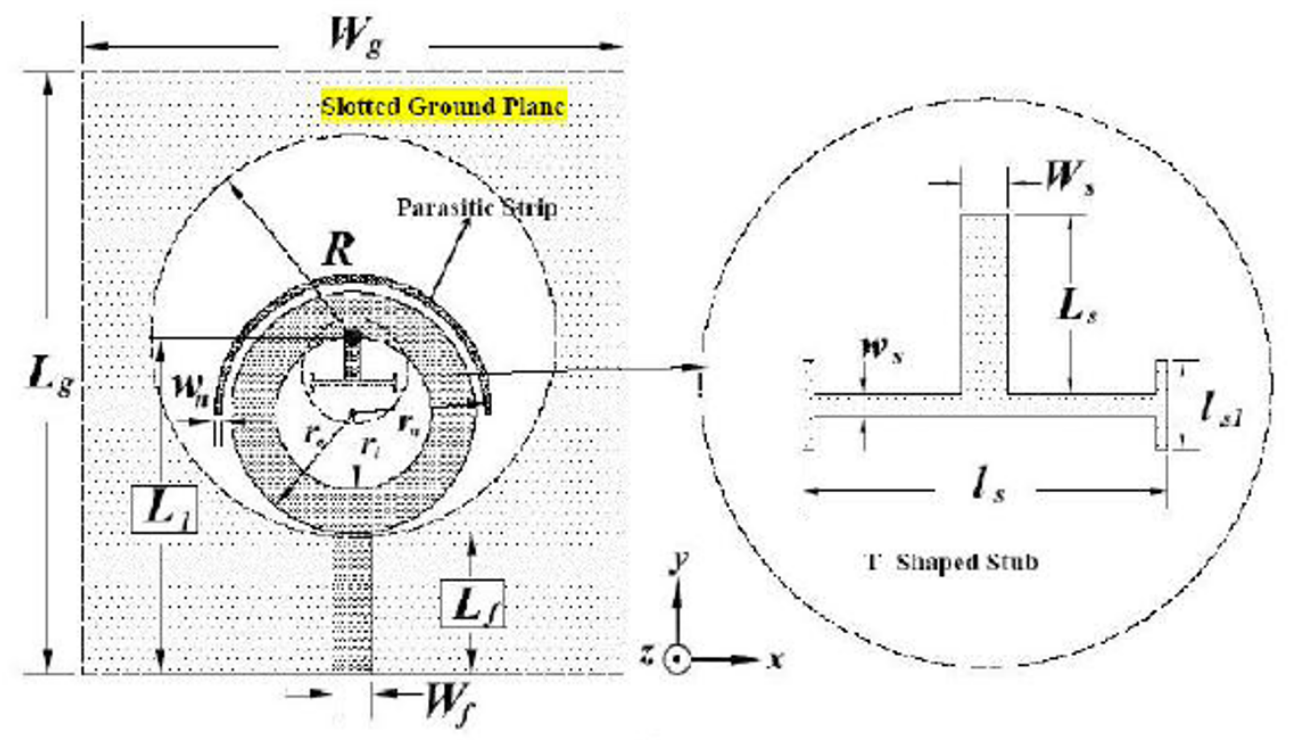

(a)
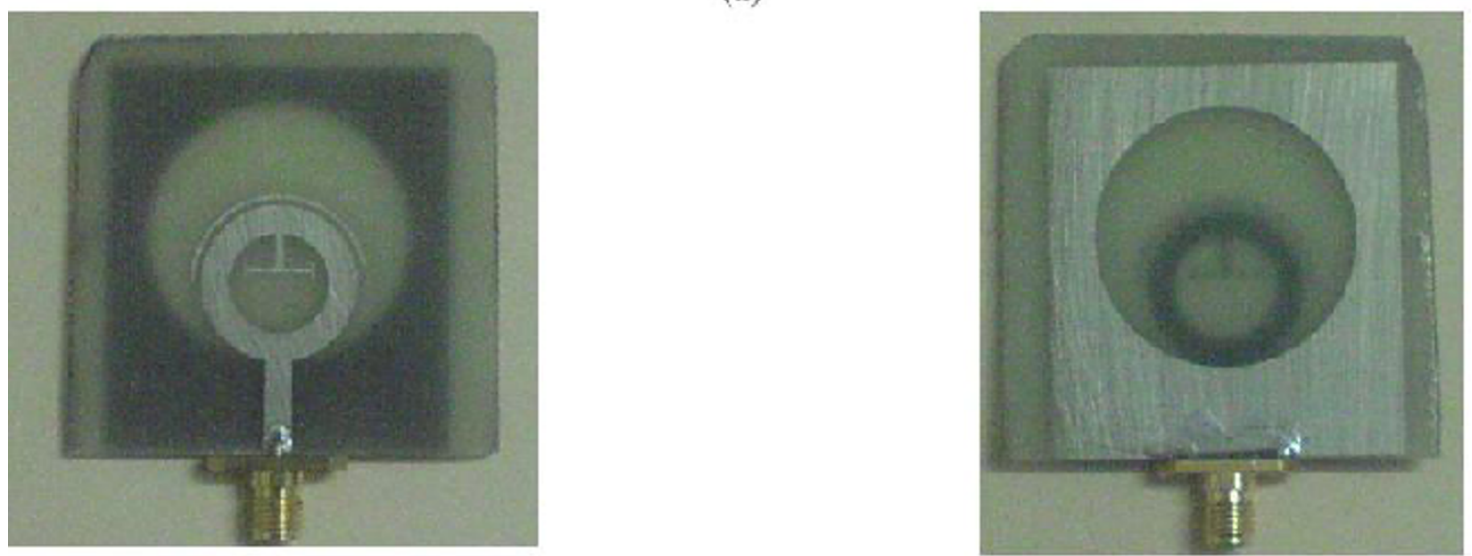

(b)

Figure 1 Geometry of proposed dual-band-notched UWB antenna. (a) Schematic and (b) photograph of fabricated antenna. 


\section{Parametric study of antenna}

To achieve the desired band-notched characteristics, the effect of the parasitic annular strip and T-shaped stub parameters on the antenna's performance was studied.

The simulated VSWR of the antenna for different values of $r_{n}$ is plotted in Figure 2. This figure shows that by increasing the $r_{n}$ the second notching frequency shifts toward lower frequencies and its bandwidth corresponding increases too.

Figure 3 shows the SWR curve of the proposed antenna for different values of $L_{s}$. It can be observed that in this case the first notch's center frequency decreases with the increase of the length of $L_{s}$.

The effect of parameter $l_{s}$ of $\mathrm{T}$-shaped stub on the antenna's performance is depicted in Figure 4. It is clear from this figure that the first notched band shifts toward lower frequencies by increasing the length of $l_{s}$.

As observed, the filtering frequencies can be tuned by varying the principal parameters of parasitic annular strip and T-shaped stub.

\subsection{VSWR}

The simulated and measured VSWR curves of the proposed dual-band-notched UWB antenna, whose dimensions are defined in Table 1 are depicted in Figure 5.

From this figure, we can see that the calculated bandwidth of the proposed antenna for which VSWR $\leq 2$ is from 2.7 to greater than $10 \mathrm{GHz}$ with two notched frequency bands of 3.5-4.4 GHz (consist of frequency band of C-band satellite communication system) and 5-6 GHz (frequency band of WLAN systems) for VSWR $\geq 2$. The measured 3-dB bandwidth of fabricated antenna is from 2.3 to greater than $11 \mathrm{GHz}$ with VSWR $\leq 2$, and the notched bandwidths are over 3.5-4.35 and over 5.05-

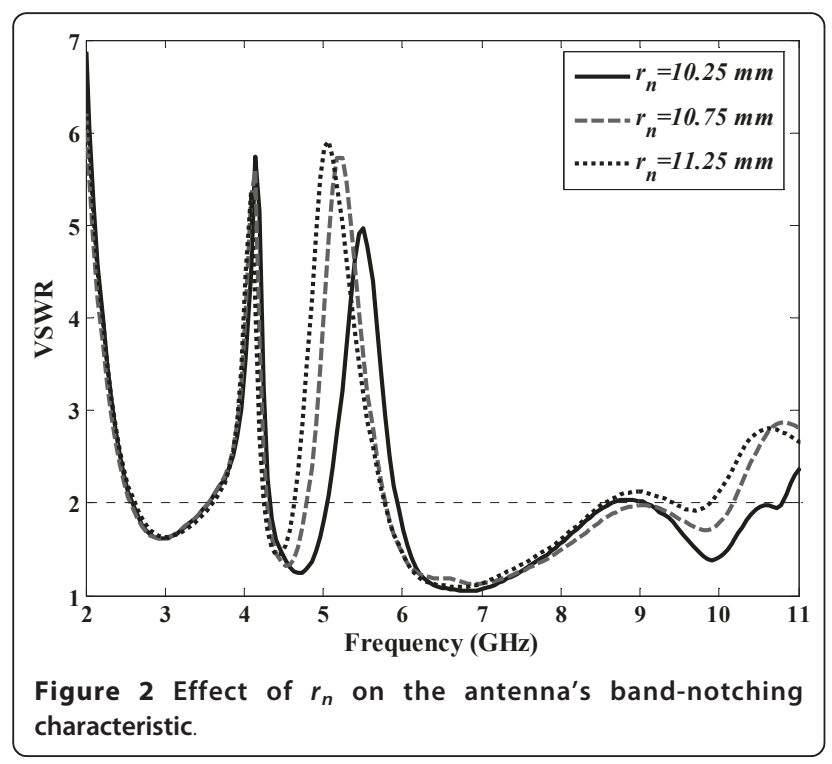

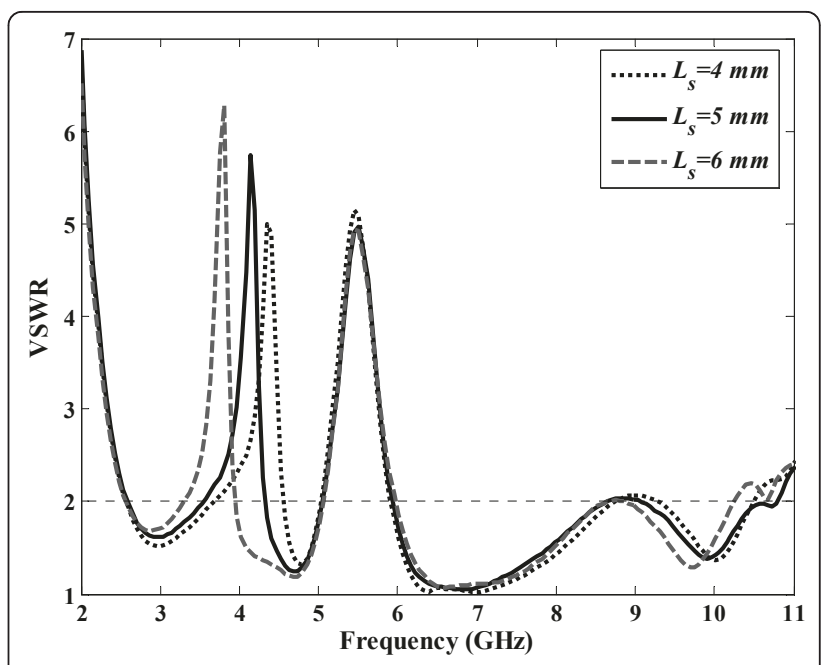

Figure 3 Effect of parameter $L_{s}$ of T-shaped stub on the antenna's band-notching characteristic.

$5.95 \mathrm{GHz}$ for $\mathrm{VSWR} \geq 2$. The measured frequency range encompasses the commercial UWB band (3.1-10.6 $\mathrm{GHz}$ ), and the notch functions reject the frequency bands of C-band satellite communication and IEEE 802.11a to overcome EMI problems of UWB systems with WLAN and C-band satellite communication systems. The correlation between the numerical and experimental results is considered to be excellent.

\subsection{Radiation patterns and gain}

The simulated and measured antenna gain in the entire UWB band is presented in Figure 6, which shows sharp gain decreases occur both in 3.6-4.2 and 5-6 GHz bands. However, for other frequencies outside the

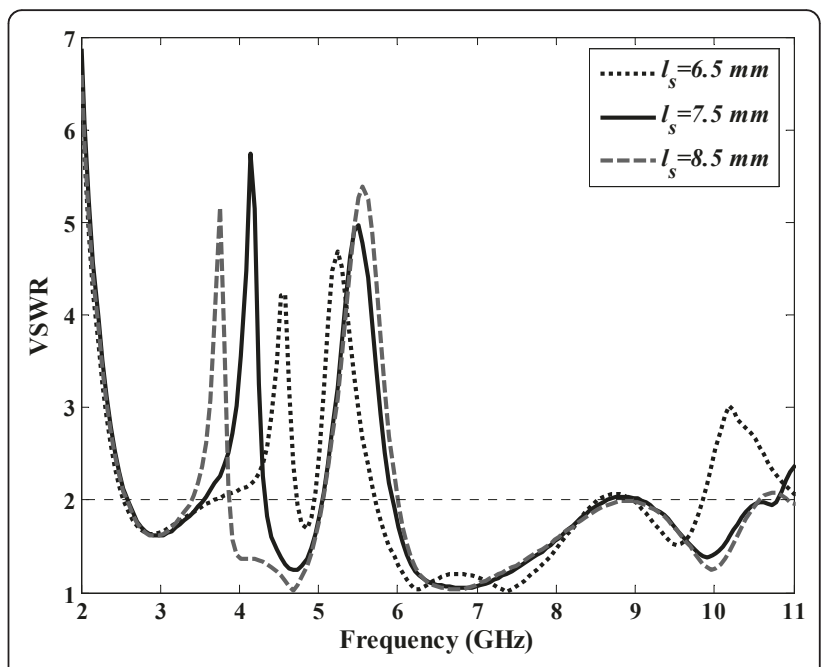

Figure 4 Effect of parameter $I_{s}$ of T-shaped stub on the bandnotched characteristics. 
Table 1 Dimensions of the proposed UWB antenna

\begin{tabular}{rr}
\hline Parameter & Value $(\mathbf{m m})$ \\
\hline$W_{\mathrm{g}}$ & 40 \\
$L_{g}$ & 45 \\
$R$ & 15 \\
$r_{\mathrm{o}}$ & 9 \\
$r_{\mathrm{i}}$ & 6 \\
$W_{f}$ & 3 \\
$L_{f}$ & 10.6 \\
$L_{1}$ & 25.2 \\
$L_{s}$ & 5 \\
$W_{s}$ & 1 \\
$I_{s 1}$ & 7 \\
$I_{s 2}$ & 2 \\
$W_{s}$ & 0.5 \\
$r_{n}$ & 10.25 \\
$W_{n}$ & 0.5 \\
\hline
\end{tabular}

rejected bands, the antenna gain is nearly constant in the entire UWB band.

The measured and simulated radiation patterns of proposed dual-band-notched UWB antenna in the Eplane ( $y z$-plane) and H-plane ( $x z$-plane) for three different frequencies 3.3, 7, and $10 \mathrm{GHz}$ are shown in Figure 7. The patterns in the $\mathrm{H}$-plane are quite omni-directional as expected. In the E-plane, the radiation patterns remain roughly a dumbbell-shape like bidirectional patterns.

\subsection{Input impedance}

Figure 8 shows the input impedance curve of the proposed dual-band-notched UWB antenna. In the notched frequency bands, it could be obviously investigated that the imaginary component curve shows parallel

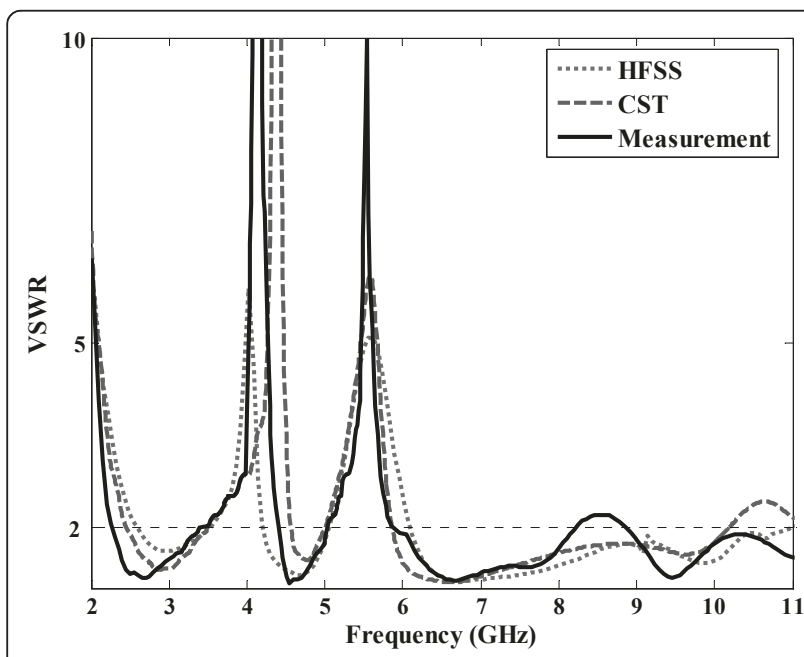

Figure 5 Simulated and measured VSWR of proposed dualband-notched UWB antenna.

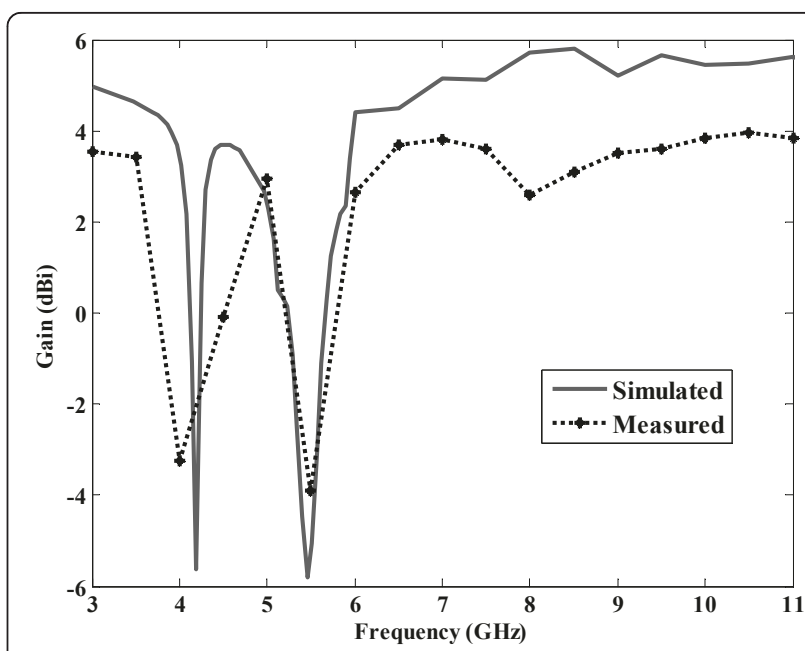

Figure 6 Gain of proposed dual-band-notched UWB antenna.

resonances and the real component presents high resistance characteristics. As a result of impedance curve of proposed antenna, it is suggested that the input impedance of the notched antenna is equivalent to the input

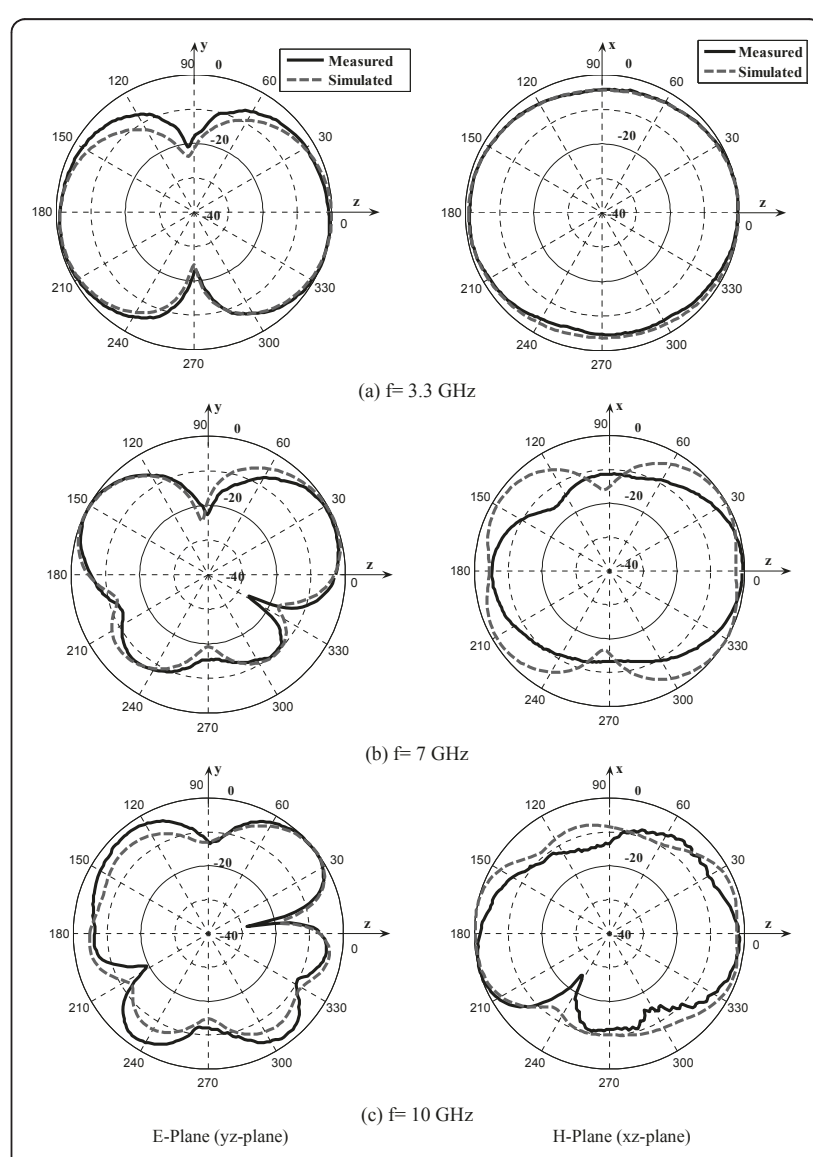

Figure 7 Simulated and measured radiation patterns of proposed dual-band-notched antenna at some frequencies. 


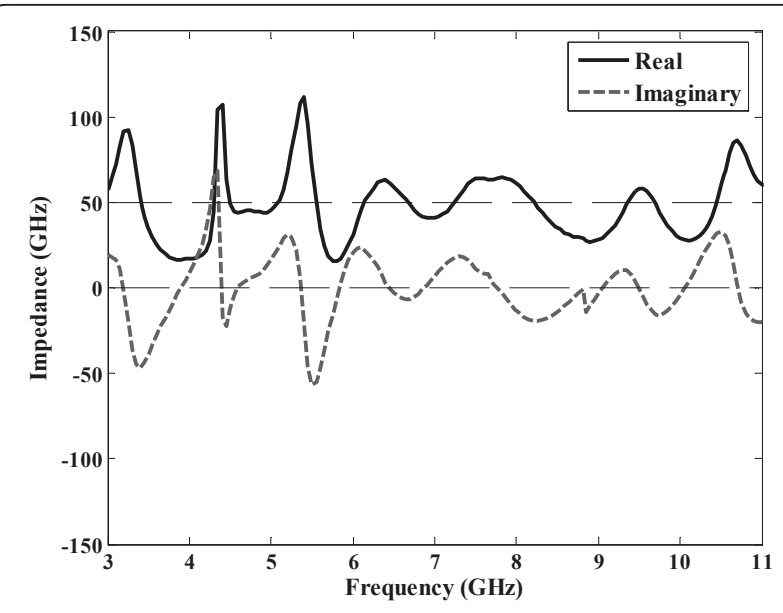

Figure 8 Curves of the measured input impedance of proposed dual-band-notched antenna.

impedance $R_{a}$ of the un-notched reference antenna connected with two parallel LC-resonant circuits in series. The corresponding conceptual circuit model is shown in Figure 9.

When the proposed antenna is operating at the two desired notched frequencies, the two corresponding LCresonant circuits mentioned above will be syntonic, which leads to the input impedance to be opened. Therefore, proposed band-notched UWB antenna presents high impedance characteristics at notched frequencies.

\section{Results and discussions}

The simulated and measured results of VSWR, radiation patterns, gain, and input impedance of the proposed antenna are presented in this section. The simulations were performed using Ansoft HFSS and CST Microwave Studio, which utilize numerical methods for electromagnetic computations. The VSWR and input impedance of antenna was measured by the Agilent 8722ES network analyzer and radiation characteristics measurements

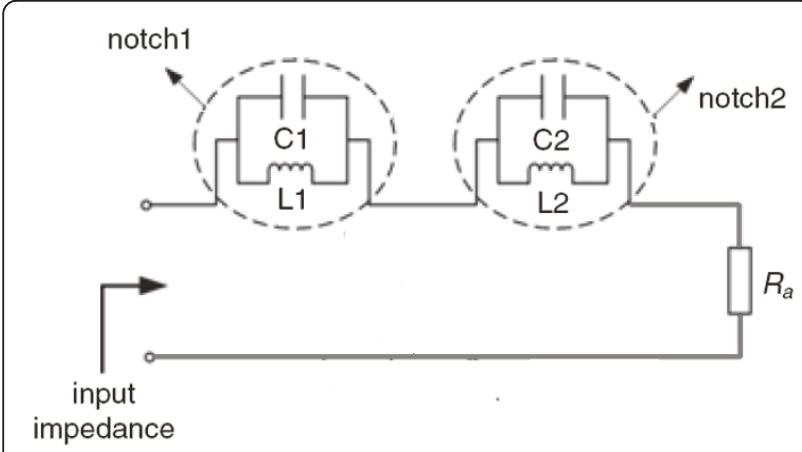

Figure 9 The suggested conceptual circuit model for proposed dual-band-notched antenna. were performed in anechoic chamber of antenna laboratory of Iran Research Institute for ICT (ITRC).

\section{Conclusion}

A circular slot UWB antenna with dual-band-notched characteristics at C-band (3.7-4.2 GHz) satellite communication systems and WLAN frequencies has been proposed and fabricated. The measurements show that VSWR is below 2 within the desired frequency bandwidth from 2.3 to greater than $11 \mathrm{GHz}$, whereas two notched frequency bands of 3.5-4.35 and 5.05-5.95 GHz for VSWR $\geq 2$ are obtained. The stable radiation patterns and constant gain in the UWB band, with the exception of notched bands, are obtained. To discuss the mechanism of the filtering properties, a conceptual circuit model based on the dual-band-notched phenomenon has been proposed. Accordingly, the proposed antenna is expected to be a good candidate in various UWB systems.

\section{Acknowledgements}

The authors would like to thank the Islamic Azad University Science \& Research Branch (SRBIAU) and Iran Research Institute for ICT (ITRC) for bracing this research.

\section{Author details}

${ }^{1}$ Science and Research Branch, Faculty of Engineering, Islamic Azad University, Tehran, Iran ${ }^{2}$ Department of Electrical Engineering, Faculty of Engineering, Shahed University, Tehran, Iran

\section{Competing interests}

The authors declare that they have no competing interests.

Received: 23 February 2011 Accepted: 5 September 2011 Published: 5 September 2011

\section{References}

1. First Report and Order, Revision of Part 15 of the Commission's Rule Regarding Ultra-Wideband Transmission System FCC 02-48, Federal Communications Commission (2002)

2. TG Ma, SK Jeng, Planar miniature tapered-slot-fed annular slot antennas for ultra-wideband radios. IEEE Trans Antennas Propag. 53, 1194-1202 (2005)

3. CY Huang, WC Hsia, Planar elliptical antenna for ultra wideband communications. Electron Lett. 41, 296-297 (2005). doi:10.1049/el:20057244

4. J Liang, CC Chiau, XD Chen, CG Parini, Study of a printed circular disC monopole antenna for UWB systems. IEEE Trans Antennas Propagat. 53(11), 3500-3504 (2005)

5. $\mathrm{P} L i, J$ Liang, $X$ Chen, Study of printed elliptical/circular slot antennas for ultra-wideband applications. IEEE Trans Antenna Propagat. 54(6), 1670-1675 (2006). doi:10.1109/TAP.2006.875499

6. YC Lin, KJ Hung, Compact ultra wideband rectangular aperture antenna and band-notched designs. IEEE Trans Antennas Propagat. 54, 3075-3081 (2006)

7. AAL Neyestanak, AA Kalteh, Band-notched elliptical slot UWB microstrip antenna with elliptical stub filled by the H-shaped slot. J Electromag Waves Appl. 22(14-15), 1993-2002 (2008)

8. K-H Kim, S-O Park, Analysis of the small band-rejected antenna with the parasitic strip for UWB. IEEE Trans Antennas Propagat. 54(6), 1688-1692 (2006). doi:10.1109/TAP.2006.875911

9. YC Lin, KJ Hung, Compact ultra wideband rectangular aperture antenna and band-notched design. IEEE Trans Antennas Propagat. 54, 3075-3081 (2006)

10. R Fallahi, A-A Kalteh, MG Roozbahani, A novel UWB elliptical slot antenna with band-notched characteristics. Progress Electromag Res PIER. 82, 127-136 (2008) 
11. AA Kalteh, R Fallahi, MG Roozbahani, A novel microstrip-Fed UWB circular slot antenna with 5-GHz band-notch characteristics, in Proceedings of the 2008 IEEE International Conference on Ultra-wideband (ICUWB2008) 1, $117-120(2008)$

12. M Naser-Moghadasi, GR DadashZadeh, A-A Kalteh, Bal VirdeeS, Design of a novel band-notched slot patch antenna for UWB communication systems. Microwave Opt Technol Lett. 52(7), 1599-1603 (2010). doi:10.1002/ mop. 25237

13. YH Zhao, JP Xu, K Yin, Dual band-notched ultra-widebandmicrostrip antenna using asymmetrical spurlines. Electron Lett. 44(18), 1051-1052 (2008). doi:10.1049/el:20081695

14. Q-X Chu, Y-Y Yang, A compact ultrawideband antenna with $3.4 / 5.5 \mathrm{GHz}$ dual band-notched characteristics. IEEE Trans Antennas Propagat. 56, 3637-3644 (2008)

15. Ansoft High Frequency Structure Simulation (HFSS), Version 10 (Ansoft Corporation, 2005)

16. Computer Simulation Technology (CST) Microwave Studio Software, Version 5.0

doi:10.1186/1687-1499-2011-88

Cite this article as: Kalteh et al:: Implementation and investigation of circular slot UWB antenna with dual-band-notched characteristics.

EURASIP Journal on Wireless Communications and Networking 2011 2011:88.

\section{Submit your manuscript to a SpringerOpen ${ }^{\mathcal{O}}$ journal and benefit from:}

- Convenient online submission

- Rigorous peer review

- Immediate publication on acceptance

- Open access: articles freely available online

- High visibility within the field

- Retaining the copyright to your article

Submit your next manuscript at $\gg$ springeropen.com 